\title{
Synthesis of antibacterial poly(o-chloroaniline)/chromium hybrid composites with enhanced electrical conductivity
}

\author{
Mirza Nadeem Ahmad ${ }^{1 * \dagger}$, Fakher Rafique ${ }^{1 \dagger}$, Faisal Nawaz ${ }^{2}$, Tahir Farooq ${ }^{1}$, Muhammad Naveed Anjum ${ }^{1 *}$, \\ Tajamal Hussain ${ }^{3}$, Sajjad Hassan ${ }^{1}$, Madeeha Batool ${ }^{3}$, Hamad Khalid $^{4}$ and Khurram Shehzad ${ }^{5}$
}

\begin{abstract}
Electrically conductive polyorthochloroaniline/chromium nanocomposites (POC/Cr NCs) were prepared by in situ chemical oxidative polymerization of orthochloroaniline in the presence of $\mathrm{Cr}$ nanoparticles (Cr NPs). The load percentage of $\mathrm{Cr}$ nanofiller was varied in POC matrix to investigate the effect of $\mathrm{Cr}$ nanoparticles on the properties of the nanocomposites. The composition, structure, and morphology of POC and its composites were examined by Scanning electron microscopy, Fourier transform infrared spectroscopy, and UV-visible spectroscopic analysis. The antibacterial potential of POC and its composites was evaluated by the disc diffusion method against Escherichia coli and Bacillus subtilis. The results showed the improved antibacterial potential with the increase in the load percentage of nanofiller. The electrical conductivity of polymer and its composites was measured and correlated with the load percentage. The results showed that electrical conductivity of the composites was enhanced with the increase in load percentage of $\mathrm{Cr}$ nanoparticles.
\end{abstract}

Keywords: Polyorthochloroaniline, Chromium nanoparticles, Conductivity, Nanofiller, Nanocomposite

\section{Introduction}

Conductive polymers are a class of synthetic metals which combine chemical and mechanical properties of polymers with electronic properties of semiconductors and metals $[1,2]$. Typical conducting polymers include polyacetylene, polyaniline, polypyrrole, polythiophene, poly( $p$-phenylene), poly(phenylenevinylene), and polyfuran [3]. Ease of synthesis, ecological stability, easy transformation to cathodic protection, and distinct electronic, magnetic, biological and optical properties have attracted researchers to focus on polyaniline and its derivatives [4]. Organic-inorganic composite materials

\footnotetext{
*Correspondence: pioneerravian@yahoo.com; anjumccj@hotmail.com ${ }^{\dagger}$ Mirza Nadeem Ahmad and Fakher Rafique contributed equally to this work 1 Department of Applied Chemistry, Government College University, Faisalabad 38030, Pakistan

Full list of author information is available at the end of the article
}

have attracted considerable attention because they can combine the advantages of both components and may provide special properties through synergistic effects [5]. To advance and expand the scope of the conductive organic materials, inorganic materials like metals and metal oxides have been incorporated to form highly functionalized materials for various applications in the fields of electronics, sensors, catalysis, energy, electromagnetic interference shielding and biomedicine $[6,7]$. The nanoscale inorganic fillers have a high surface to volume ratio and therefore are expected to modify the biological, optical, electrical, thermal and dielectric polymers drastically [8]. Recently, metals and metal oxide particles have been incorporated in the conductive polymers to form nanocomposite (NCs). NCs show combination of properties such as conductivity, catalytic, electrochemical, optical and antimicrobial properties [9]. Chemically synthesized nanoparticles have attracted much attention because of the unique properties associated with their 
magnitude of size and of its uniform distribution [10]. Because of their small size, nanoparticles have properties of advanced materials that are significantly different from those of their bulk counterparts [11]. Therefore, the addition of nanofiller to an inherently conductive polymer could produce the materials with an even high level of conductivity [12-20]. Recently, the demand for conducting plus antibacterial materials has increased manifold due to their tunable properties which makes them suitable for different areas of application.

In the present study, we report the preparation of chloro-functionalized PANI, i.e. poly(o-chloroaniline). POC was further composited with $\mathrm{Cr}$ nanofiller to synthesize the materials with enhanced electrical conductivity and antibacterial action. Oxidative polymerization technique was employed for in situ syntheses of $\mathrm{POC} / \mathrm{Cr}$ $\mathrm{NCs}$ by using ammonium persulfate as an oxidizing agent in the presence of $\mathrm{Cr}$ nanofiller and 4,4'-diaminodiphenylamine. Furthermore, we have studied the antibacterial and electrical properties of the composite materials and effect of nanofiller load percentage.

\section{Materials and methods \\ Materials}

Orthochloroaniline, 4,4'-diaminodiphenylamine (DDPA) and ammonium persulfate (APS) were procured from Sigma-Aldrich (Germany). The chromium nanoparticles were purchased from GNM Corporation France and utilized without any treatment. All the chemicals and reagents were of analytical grade and used as received.

\section{Synthesis of poly(o-chloroaniline)}

Polyorthochloroaniline was polymerized by acid catalyzed oxidative polymerization of $o$-chloroaniline. Specifically, $5 \mathrm{~g}$ of $o$-chloroaniline (monomer) and $0.5 \mathrm{~g}$ of 4,4'-diaminodiphenylamine were dissolved in $20 \mathrm{ml}$ of $1 \mathrm{M} \mathrm{HCl}$ to prepare solution A. DDPA was added $10 \%$ weight of the monomer. The temperature of solution A was maintained at $4{ }^{\circ} \mathrm{C}$ in an ice bath. The solution B was prepared by dissolving $5 \mathrm{~g}$ of ammonium persulfate in $20 \mathrm{ml}$ of $1 \mathrm{M} \mathrm{HCl}$. The monomer to APS mass ratio was kept as 1:1. Solution A was kept on magnetic stirring in an ice bath and solution $B$ was then added drop wise into solution A for $3 \mathrm{~h}$. The color of the solution was turned green which indicated the polymerization process. The stirring was stopped and the solution was kept undisturbed for $24 \mathrm{~h}$. Then, the solution was centrifuged at 4000 RPM and washed first with double distilled and methanol at the last. Finally, the product was dried in a vacuum oven at $100{ }^{\circ} \mathrm{C}$ for $1 \mathrm{~h}$. The de-doping and redoping were performed using $1 \mathrm{M} \mathrm{HCl}$, and then with $1 \mathrm{M} \mathrm{NH}_{4} \mathrm{OH}$. After de-doping, the color was turned from

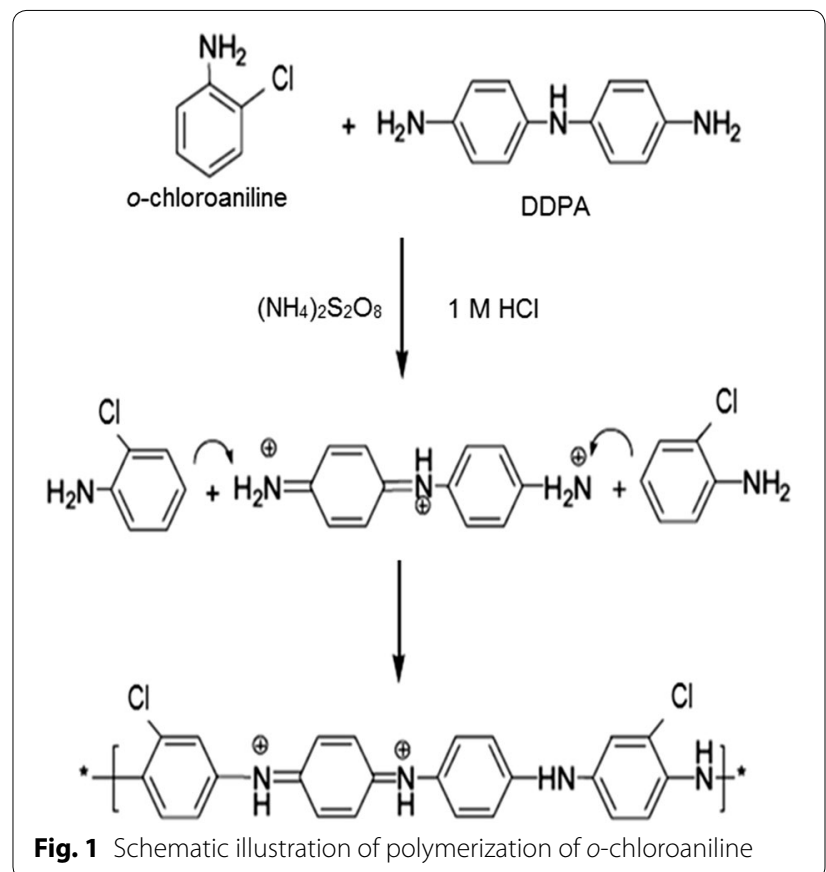

green to blue and it was reverted to its original color after re-doping with acid [21] (Fig. 1).

\section{Synthesis of poly(o-chloroaniline)/chromium nanocomposites}

Nanocomposites of POC and Cr NPs were prepared by following the similar procedure as employed for the polymerization of $o$-chloroaniline. According to the desired weight percentage, the Cr NPs were added to the monomer at the time of polymerization. The $o$-chloroaniline along with DDPA was dissolved in $1 \mathrm{M} \mathrm{HCl}$ and then $\mathrm{Cr}$ NPs were added to this solution. The contents were sonicated for $15 \mathrm{~min}$ to prepare the uniform dispersion. After sonication, the mixture was stirred continuously via magnetic stirrer and APS solution was added drop wise as an oxidizing agent. The temperature was maintained at $4{ }^{\circ} \mathrm{C}$ during the reaction. By following the above recipe, all other composites were prepared by varying the Cr NPs load percentage (1, 3, 5, 7 and 10\%). After adding the APS, the solution was kept on stirring for $3 \mathrm{~h}$. The formation of green color showed the preparation of the product. Finally, the solution was centrifuged and washed with water and methanol. The products were then dried in a vacuum oven at $100{ }^{\circ} \mathrm{C}$ for $3 \mathrm{~h}$ and proceeded for characterization.

\section{Characterization}

Various analytical tools were used to characterize the structure, morphology, and properties of POC and POC/ $\mathrm{Cr}$ nanocomposites. UV-visible spectra were obtained 
from UV-visible spectrophotometer (Varian Cary 50) in the scanning range of $200-800 \mathrm{~nm}$ at the scanning rate of $400 \mathrm{~nm} / \mathrm{min}$. The baseline line correction was done by distilled water as a blank reference. FTIR spectra were recorded from FTIR spectrometer (Impact 400, Nicolet, Waltham, MA) in the range of $400-4000 \mathrm{~cm}^{-1}$ by $\mathrm{KBr}$ pellet method. SEM images were obtained from Hitachi S-4700 operating at $30 \mathrm{kV}$. The antibacterial potential was evaluated by the agar disc diffusion method. The electrical conductivity was recorded by using CyberScan PC 510 conductivity meter. The conductivity of the dispersion was measured containing $2 \mathrm{mg}$ of sample in $1 \mathrm{ml}$ of deionized water.

\section{Results and discussion}

Polyorthochloroaniline/chromium nanocomposites were characterized by using FTIR, UV-visible, SEM and electrical conductivity measurements.

\section{FTIR analysis of POC and POC/Cr NCs}

Polyorthochloroaniline/chromium nanocomposites were analyzed using FTIR technique. It is employed to determine the different vibrational modes shown by the polymer and its composites. The FTIR spectra of polymer and polymer nanocomposites were recorded and positions of the absorption peaks were identified. The prominent bands appeared at 1201 and $1499 \mathrm{~cm}^{-1}$ due to non-symmetric stretching vibrations of C-6 rings. The infrared spectrum of POC derivatives showed the bands around 955, 875, 785, 720 and $655 \mathrm{~cm}^{-1}$ which were assigned to ortho-substituted aryl rings. The signal at $3075 \mathrm{~cm}^{-1}$ was evident for stretching vibrations of $-\mathrm{NH}$ group present in the polymer. Strong peaks at 1580 and $1515 \mathrm{~cm}^{-1}$ were due to benzene rings and quinonoid structure present in the polymer. The stretching vibrational signal of aromatic $-\mathrm{CN}$ was appeared at $1305 \mathrm{~cm}^{-1}$. The important two peaks were recorded at 918 and $833 \mathrm{~cm}^{-1}$ and were assigned to out-of-plane bending vibrations of $-\mathrm{CH}$ in 1,2,4-trisubstituted aromatic rings. The chloro group, at the ortho position on the phenyl ring, was indicated by a signal at $750 \mathrm{~cm}^{-1}$. All the signals confirmed the synthesis of the polymer and its composites. On the addition of Cr nanofiller, the bands between 3710 and $3510 \mathrm{~cm}^{-1}$ were shifted towards
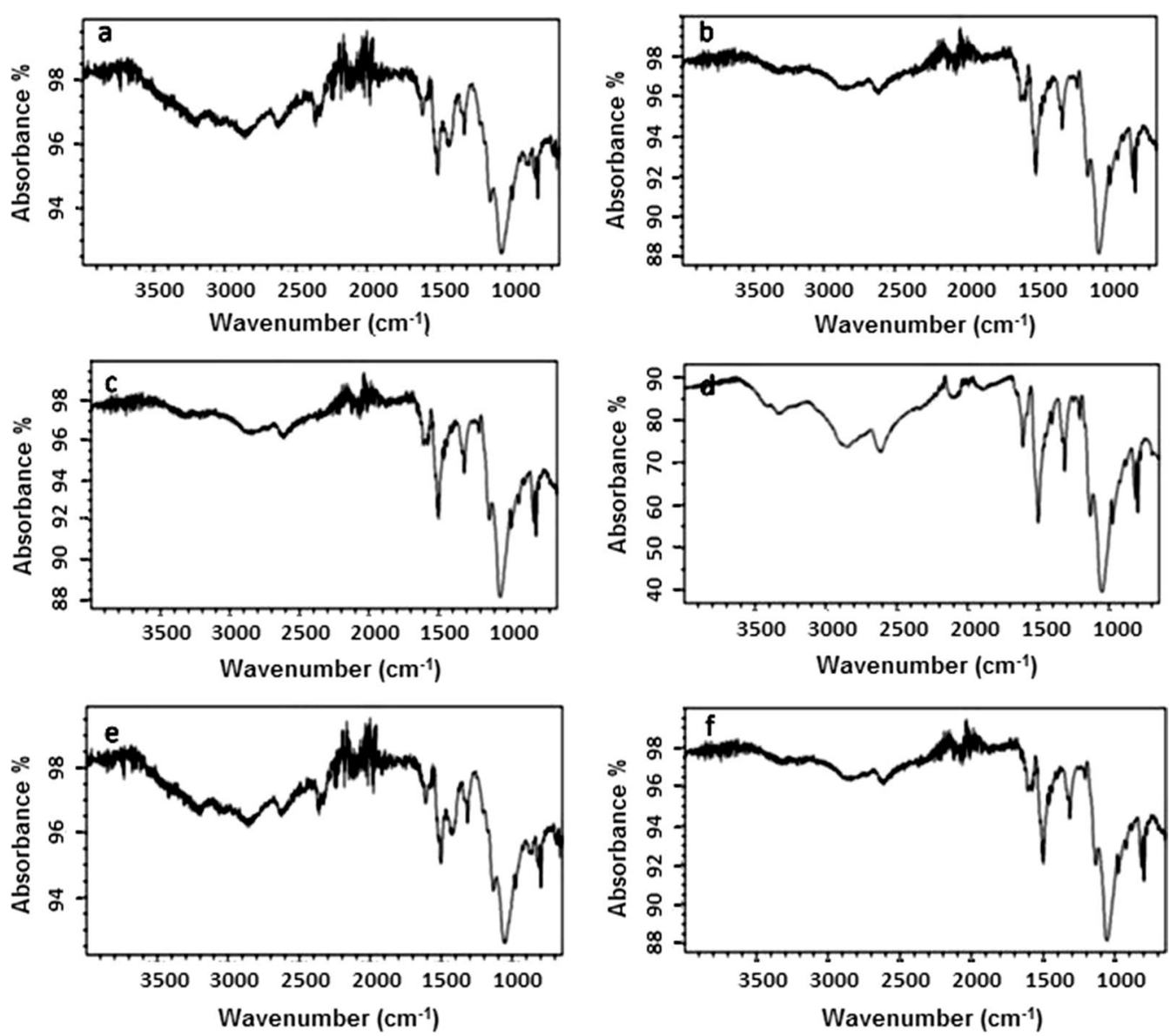

Fig. 2 FTIR spectra of a POC, and POC/Cr NCs containing b $1 \%$ Ni NPs, c 3\% Ni NPs, d $5 \%$ Ni NPs, e 7\% Ni NPs, f $10 \%$ Ni NPs 
lower values and became deeper and wider. This absorption behavior showed the presence of nanofiller in the polymer matrix. In the spectra of $\mathrm{POC} / \mathrm{Cr} \mathrm{NCs}$, the $\mathrm{NH}$ stretching frequency peak appeared at $3385 \mathrm{~cm}^{-1}$, while it was present at $3410 \mathrm{~cm}^{-1}$ in the case of POC. The characteristic peaks of quinonoid and benzenoid rings of poly (o-chloroaniline) were located at 1580 and $1505 \mathrm{~cm}^{-1}$ and aromatic $-\mathrm{CN}$ stretching mode appeared at $1300 \mathrm{~cm}^{-1}[21,22]$.

The bands at 895 and $825 \mathrm{~cm}^{-1}$ showed in-plane bending vibrations of $-\mathrm{CH}$ present in 1,2,4-trisubstituted aromatic rings. In POC, these bands were located at 920 and $835 \mathrm{~cm}^{-1}$. The peak due to chloro group attached to the phenyl ring transition shifted to $755 \mathrm{~cm}^{-1}$. When all the peaks of the POC/Cr NCs were compared with POC, it was noted that all the special stretching frequencies were shifted towards the lower frequency. This shift was attributed to the addition of the nanofiller. The FTIR studies confirmed the structural feature of the materials synthesized. The results of FTIR analysis for POC/Cr NCs containing other load percentages were also on the same pattern [23, 24] (Fig. 2).

\section{UV-VIS absorption of POC and POC/Cr NCs}

UV-visible absorptions $\mathrm{POC} / \mathrm{Cr} \mathrm{NCs}$ were measured on UV-visible spectrophotometer in the range of $200-800 \mathrm{~nm}$ using distilled water as reference solvent. The prominent band was recorded at $252 \mathrm{~nm}$. The
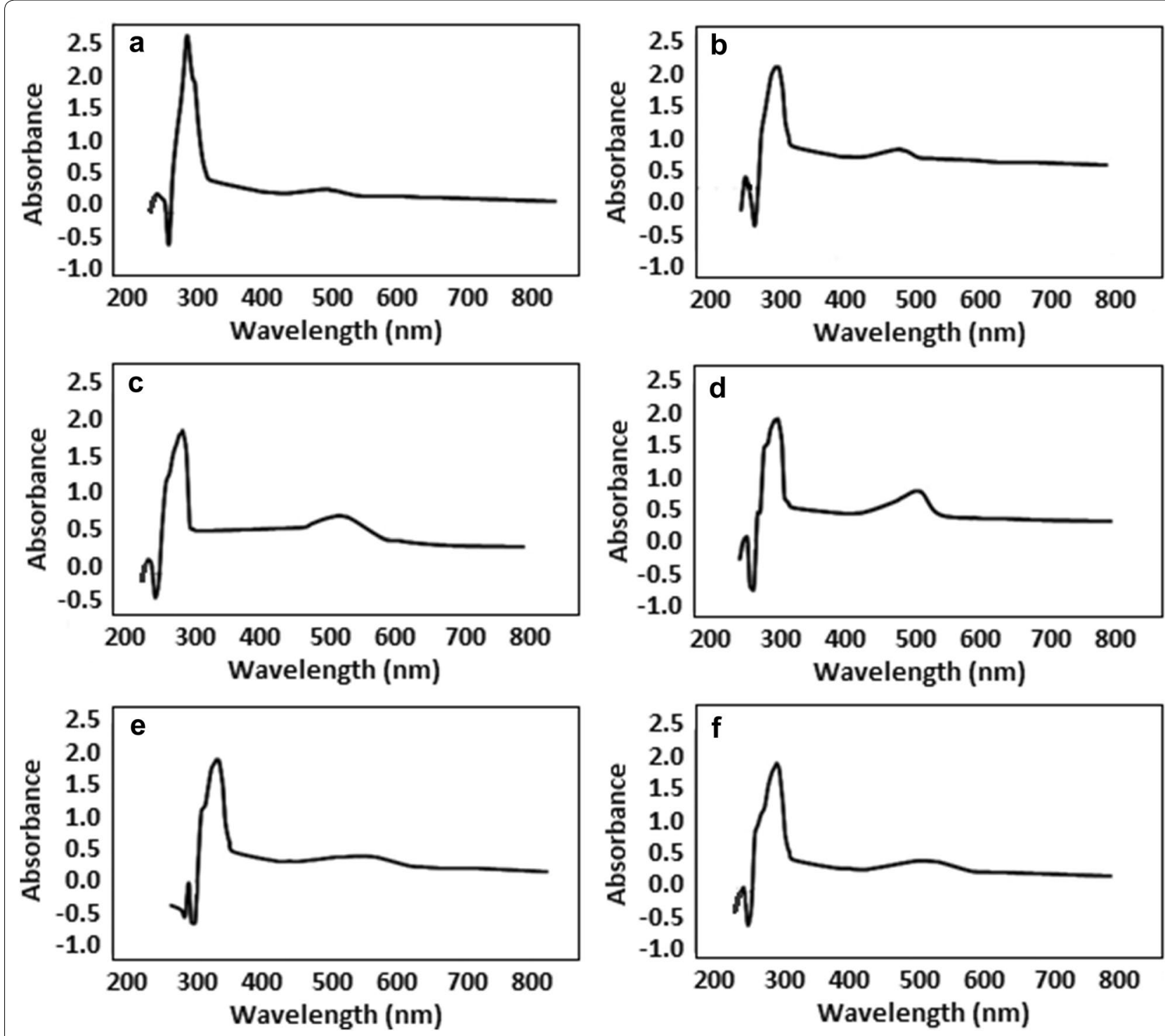

Fig. 3 UV-Visible spectra of a POC, and POC/Cr NCs containing b $1 \%$ Ni NPs, c 3\% Ni NPs, d $5 \%$ Ni NPs, e 7\% Ni NPs, f $10 \%$ Ni NPs 
absorption band at $252 \mathrm{~nm}$ was evident for $\pi-\pi^{*}$ transitions associated with benzene rings and others were due to $n-\pi^{*}$ transitions of quinonoid rings in the range of $317-320 \mathrm{~nm}$. With the increase in the load percentage of $\mathrm{Cr}$ nanofiller, there was a gradual increase in the intensity of these bands. The absorptions of $\mathrm{POC} / \mathrm{Cr} \mathrm{NCs}$ were shifted towards lower wavelengths compared with POC. The blue shift indicated the embedding of $\mathrm{Cr}$ nanoparticles in the POC matrix [23, 24].

Due to the addition of $\mathrm{Cr}$ nanofiller, the $\mathrm{n}-\pi^{*}$ absorption band became slightly wider while it was sharper in case of POC. This phenomenon showed some physical interaction between the polymer matrix and $\mathrm{Cr}$ nanoparticles. POC/Cr NC (1\%) showed the characteristic band at $320 \mathrm{~nm}, \mathrm{POC} / \mathrm{Cr} \mathrm{NC}(7 \%)$ at $318 \mathrm{~nm}$ and $\mathrm{POC} / \mathrm{Cr}$ $\mathrm{NC}(10 \%)$ at $317 \mathrm{~nm}$. The results demonstrated the good absorption of UV-visible radiation by the NCs (Fig. 3).

\section{Antibacterial testing}

The POC and composites prepared were evaluated against different strains of gram-positive and gram-negative bacteria. The results showed that $\mathrm{POC} / \mathrm{Cr} \mathrm{NCs}$ were significantly inhibited the bacterial population analogous to other reported materials. The antibacterial activity of the composites was determined against $E$. coli and $B$.

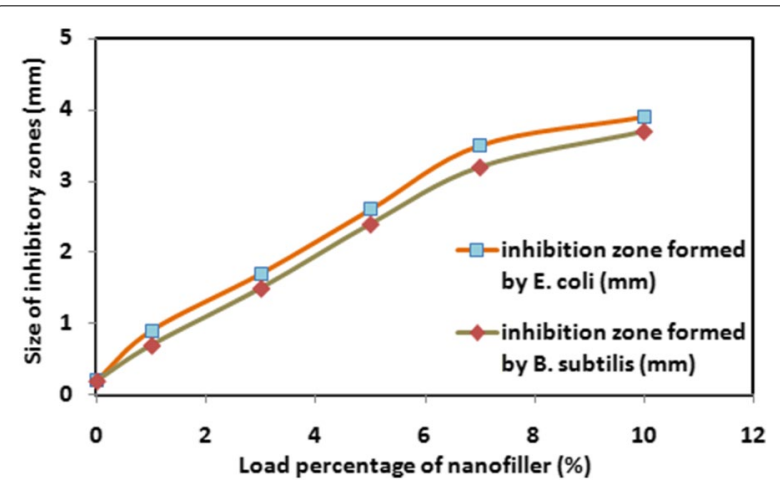

Fig. 4 Size of inhibitory zones versus load percentage of $\mathrm{Cr}$ in nanocomposites

Table 1 Size of inhibitory zones of antibacterial test of the POC/Cr nanocomposites

\begin{tabular}{lll}
\hline Load percentage of nanofiller (\%) & \multicolumn{2}{l}{$\begin{array}{l}\text { Size of inhibitory zones } \\
(\mathbf{m m})\end{array}$} \\
\cline { 2 - 3 } & E. coli & B. subtilis \\
\hline $1 \%$ & 0.9 & 0.7 \\
$3 \%$ & 1.7 & 1.5 \\
$5 \%$ & 2.6 & 2.4 \\
$7 \%$ & 3.5 & 3.2 \\
$10 \%$ & 3.9 & 3.7 \\
POC & 0.2 & 0.2 \\
\hline
\end{tabular}

subtilis and compared with POC as plotted in Fig. 4. The antibacterial test was carried out by standard agar disc diffusion method [24].

The composites exhibited better antibacterial potential than POC as evident from Table 1. The antibacterial activity was amplified with the increase in the load percentage of the $\mathrm{Cr}$ nanofiller. The size of inhibitory zones was measured against two bacterial strains and it is found that the size around POC was minimized. The antibacterial potential was correlated with load percentage of the nanofiller and size of inhibition zone was maximized in case of POC/Cr NCs containing 10\% Cr nanofiller. The reason was the availability of maximum inhibitory nanoparticles to counter the growth of bacteria. It is evident that composites were equally effective against both grampositive and gram-negative bacteria.

\section{SEM images of $\mathrm{POC}$ and $\mathrm{POC} / \mathrm{Cr}$ NCs}

SEM micrographs of $\mathrm{POC}$ and $\mathrm{POC} / \mathrm{Cr}$ NCs were recorded to study the morphology of the materials. The SEM images were displayed which illustrated the compactness and grainy structure of $\mathrm{POC} / \mathrm{Cr} \mathrm{NCs}$ due to the presence of nanofiller. The results exhibited the uniform dispersion of nanofiller in the polymer. The $\mathrm{POC} / \mathrm{Cr}$ NCs containing 7\% NPs was represented and explained the composite morphology of the materials. The SEM images also showed that chromium nanoparticles are fully embedded in the polymer matrix and nanocomposite became increasingly compact. Chromium nanoparticles also dispersed uniformly in the polymer although at a meager agglomeration of nanoparticles and illustrated the grainy morphology for all the polymer nanocomposites [23] (Fig. 5).

\section{Electrical conductivity measurement}

The conductivity of $\mathrm{POC} / \mathrm{Cr} \mathrm{NCs}$ was recorded and compared with $\mathrm{POC}$ as a reference. The electrical conductivity was measured by dispersion method at room temperature $\left(25^{\circ} \mathrm{C}\right)$ in $\mathrm{S} / \mathrm{cm}$ unit. The electrical conductivities of POC and POC/Cr NCs were given in Table 2 [25].

With the increase in the load percentage of $\mathrm{Cr}$ nanofiller, the conductivity was also increased. The reason is that formation of polarons in $\mathrm{POC} / \mathrm{Cr}$ nanocomposite. The increase in conductivity values was due to the interaction of conducting polymer matrix with neighboring nanoparticles [11]. The increase in conductivity POC/ $\mathrm{Cr}$ NCs graphically was represented in Fig. 6. It is evident from conductivity data, the increase in conductivity was due to the contribution of chromium nanoparticles that were embedded in POC matrix. In fact, the POC/ $\mathrm{Cr}$ composite containing $1 \% \mathrm{Cr}$ NPs showed significant improvement in the electrical conductivity compared 

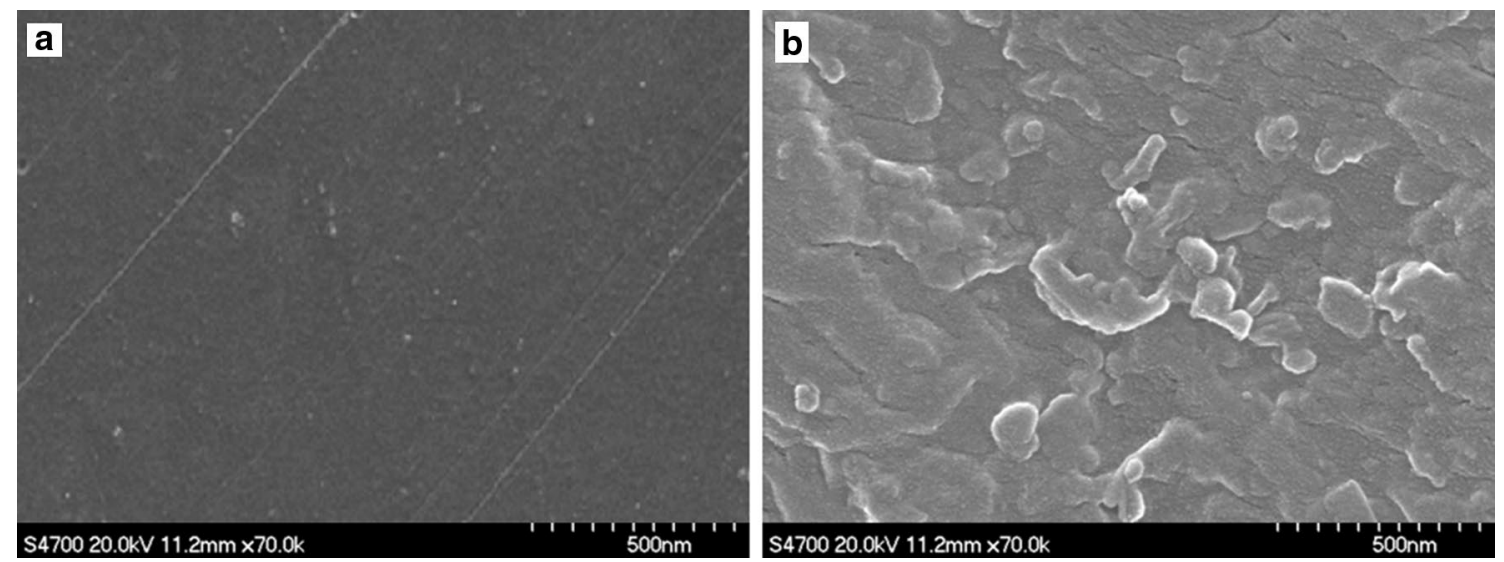

Fig. 5 SEM images of a POC and $\mathbf{b} \mathrm{POC/Cr}$ NCs containing 7\% Cr NPS

\section{Table 2 Electrical conductivity of POC/Cr NCs}

\begin{tabular}{ll}
\hline Samples & Electrical conductivity ${ }^{\mathbf{a}} \mathbf{( S / \mathbf { c m } )}$ \\
\hline $1 \%$ & 103 \\
$3 \%$ & 114 \\
$5 \%$ & 150 \\
$7 \%$ & 240 \\
$10 \%$ & 350 \\
POC & 3 \\
\hline
\end{tabular}

a At room temperature

with POC. The higher percentages of Cr NPs (3-10\%) were added just to evaluate the improvement behavior in the conductivity of the composites. The composites containing higher percentages of Cr NPs (3-10\%) showed slight improvement in the conductivity due to the agglomeration of the Cr NPs. The heavy loading of $\mathrm{Cr}$ NPs resulting in slight improvement could not be justified. Therefore, the minimum loading of Cr NPs (1\%) not only avoids the agglomeration but also makes the material cost effective.

\section{Conclusions}

In summary, synthesis of POC was carried out by oxidative polymerization of $o$-chloroaniline using ammonium sulfate as oxidizing agent and $\mathrm{HCl}$ as a doping agent. Further, POC was composited with Cr NPs by varying the load percentage of nanofiller (1-10\%). Different characterization techniques were employed to confirm the structure and properties of the nanocomposites. FTIR studies elucidated the structural features, UV-visible data demonstrated the absorption properties, and SEM imaging demonstrated the morphology of the NCs. The composites containing $10 \% \mathrm{Cr}$ nanofiller exhibited

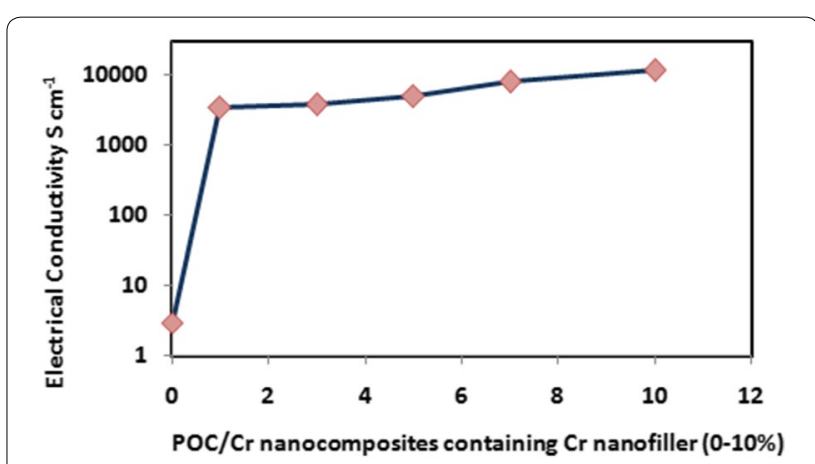

Fig. 6 Plot of electrical conductivity versus load percentage of Cr NPs in nanocomposites

maximum efficacy against E. coli and B. subtilis. The electrical conductivity measurements of $\mathrm{POC} / \mathrm{Cr} \mathrm{NCs}$ were recorded by dispersion method. The electrical conductivity values of composites containing nanofiller were better than POC. The composites formed could find the potential applications as antibacterial and conducting materials for biological and electronic devices.

\section{Abbreviations}

Cr: chromium; POC/Cr NCs: polyorthochloroaniline/chromium nanocomposites; NPs: nanoparticles; POC: polyorthochloroaniline; SEM: scanning electron microscopy; FTIR: fourier transform infrared spectroscopy; UV-visible: ultraviolet visible; PANI: polyaniline; DDPA: 4,4'-diaminodiphenylamine; APS: ammonium persulfate; E. coli: Escherichia coli; B. subtilis: Bacillus subtilis; RPS: round per minute; $\mathrm{KBr}$ : potassium bromide; $1 \mathrm{M}: 1$ molar; $\mathrm{HCl}$ : hydrochloric acid; $\mathrm{NH}_{4} \mathrm{OH}$ : ammonium hydroxide.

\section{Authors' contributions}

MNAh, FR and MNAn carried out the experiments and prepared the manuscript; FN, TF, and SH did the characterizations; TH, MB, HK and KS reviewed and polished the manuscript. All authors read and approved the final manuscript. 


\begin{abstract}
Author details
1 Department of Applied Chemistry, Government College University, Faisalabad 38030, Pakistan. ${ }^{2}$ University of Engineering \& Technology, Lahore 54000, Pakistan. ${ }^{3}$ Institute of Chemistry, University of the Punjab, Lahore 54000, Pakistan. ${ }^{4}$ Interdisciplinary Research Center in Biomedical Materials, COMSATS Institute of Information Technology, Lahore 54000, Pakistan. ${ }^{5}$ Department of Information Technology and Electronics, Zhejiang University, Hangzhou 310027, China.
\end{abstract}

\section{Acknowledgements}

All the authors have been acknowledged and mentioned in the author list.

\section{Competing interests}

The authors declare that they have no competing interests.

\section{Availability of data and materials}

All the data and materials supporting this manuscript are included in the article.

\section{Ethics approval and consent to participate}

Not applicable.

\section{Funding}

Not applicable.

\section{Publisher's Note}

Springer Nature remains neutral with regard to jurisdictional claims in published maps and institutional affiliations.

Received: 15 October 2017 Accepted: 20 April 2018

Published online: 26 April 2018

\section{References}

1. Gök A, Songül Ş (2006) Preparation and characterization of poly(2-chloroaniline)/ $/ \mathrm{SiO}_{2}$ nanocomposite via oxidative polymerization: comparative UV-vis studies into different solvents of poly(2-chloroaniline) and poly(2chloroaniline)/ $/ \mathrm{SiO}_{2}$. J Appl Polym Sci 102:935-943

2. Yuanting L, Li Z, Meng L, Zhigang P, Dawei L (2012) A disposable biosensor based on immobilization of laccase with silica spheres on the MWCNTs-doped screen-printed electrode. Chem Cent J 6(103):1-8

3. Hyeonseok Y (2013) Current trends in sensors based on conducting polymer nanomaterials. Nanomaterials 3(3):524-549

4. Edward S, Jin-Woo C (2013) Conducting polyaniline nanowire and its applications in chemiresistive sensing. Nanomaterials 3(3):498-523

5. Nandapure BI, Kondawar SB, Salunkhe MY, Nandapure AI (2013) Magnetic and transport properties of conducting polyaniline/nickel oxide nanocomposites. Adv Mater Lett 4:134-140

6. Dong L, Xue W, Jinxing D, Chenglong Z, Jinshan G, Peng L (2015) Crosslinked carbon nanotubes/polyaniline composites as a pseudocapacitive material with high cycling stability. Nanomaterials 5(2): 1034-1047

7. Tajamal H, Ahmad MN et al (2017) Surfactant incorporated Co nanoparticles polymer composites with uniform dispersion and double percolation. J Chem 2017(7191590):1-6

8. Patil SL, Chougule MA, Pawar SG, Sen S, Patil VB (2012) Effect of camphor sulfonic acid doping on structural morphological optical and electrical transport properties on loaded in orthochloropolyaniline nanocomposites. Soft Nanosci Lett 2:46-53
9. Umare SS, Shambharkar BH, Ningthoujam RS (2010) Synthesis and characterization of polyaniline- $\mathrm{Fe}_{3} \mathrm{O}_{4}$ nanocomposite: electrical conductivity magnetic electrochemical studies. Synth Met 160:17-18

10. Park J, Kang E, Son SU et al (2005) Monodisperse nanoparticles of Ni and $\mathrm{NiO}$ : synthesis characterization selfassembled superlattices and catalytic applications in the suzuki coupling reaction. Adv Mater 17:429-434

11. Ambalgi SM, Inamdar HK, Manjula VT, Nagaraja S, Hogade SG, Sannakki B (2016) Synthesis characterization and electrical properties of polyaniline/ nickel oxide nanocomposites. Int J Eng Res 5(2):119-122

12. Haba Y, Segal E, Narkis M, Titelman GI, Siegmann A (2000) A polyaniline-DBSA/polymer blends prepared via aqueous dispersions. Synth Met 110:189-193

13. Hussain T et al (2016) Polyaniline/silver decorated-MWCNT composites with enhanced electrical and thermal properties. Polym Compos. https:// doi.org/10.1002/pc.24219

14. Shehzad K et al (2015) Two percolation thresholds and remarkably high dielectric permittivity in pristine carbon nanotube/elastomer composites. Appl Nanosci 5(8):969-974

15. Shehzad Ket al (2014) Influence of carbon nanotube dimensions on the percolation characteristics of carbon nanotube/polymer composites. J Appl Phys 116(6):064908

16. Shehzad K et al (2013) Piezoresistive behavior of electrically conductive carbon fillers/thermoplastic elastomer nanocomposites. J Adv Phys 2(1):70-74

17. Shehzad K et al (2013) All-organic PANI-DBSA/PVDF dielectric composites with unique electrical properties. J Mater Sci 48(10):3737-3744

18. Shehzad K et al (2013) Effects of carbon nanotubes aspect ratio on the qualitative and quantitative aspects of frequency response of electrical conductivity and dielectric permittivity in the carbon nanotube/polymer composites. Carbon 54:105-112

19. Dang Z-M et al (2011) On refining the relationship between aspect ratio and percolation threshold of practical carbon nanotubes/polymer nanocomposites. Jpn J Appl Phys 50(8R):080214

20. Shehzad K et al (2016) Three-dimensional macro-structures of twodimensional nanomaterials. Chem Soc Rev 45(20):5541-5588

21. Anjum MN, Zhu L, Luo Z, Yan J, Tang H (2011) Tailoring of chiroptical properties of substituted polyanilines by controlling steric hindrance. Polymer 52:5795-5802

22. Linganathan P, Samuel JM (2014) Synthesis characterization and electrical conductivity of poly (2-chloroaniline)/MMT and poly(2-chloroaniline)/ $\mathrm{Na}$-bentonite nanocomposites in the presence of surfactants. Int J Sci Technol Res 3:69-75

23. Linganathan P, Sundararajan J, Samuel JM (2014) Synthesis characterization and photoconductivity studies on poly(2-chloroaniline) and poly(2chloroaniline)/CuO nanocomposite. J Compos 2014:1-9

24. Ahmad MN et al (2017) Synthesis and antibacterial potential of hybrid nanocomposites based on polyorthochloroaniline/copper nanofiller. Polym Compos. https://doi.org/10.1002/pc.24558

25. Wojturski I et al (1998) Electrical conductivity of polyaniline suspensions 2. Freezing-melting cycle. Croat Chem Acta 71(4):873-882

\section{Submit your manuscript to a SpringerOpen ${ }^{\circ}$ journal and benefit from:}

- Convenient online submission

- Rigorous peer review

- Open access: articles freely available online

- High visibility within the field

- Retaining the copyright to your article

Submit your next manuscript at $\boldsymbol{\nabla}$ springeropen.com 